\title{
GRAMÁTICA FONOLÓGICA E ENSINO DE INGLÊS COMO LÍNGUA ADICIONAL: APROXIMANDO A LINGUÍSTICA FORMAL DA LINGUÍSTICA APLICADA
}

\author{
PHONOLOGICAL GRAMMAR AND THE TEACHING OF ENGLISH AS AN \\ ADDITIONAL LANGUAGE: BRINGING FORMAL \\ AND APPLIED LINGUISTICS TOGETHER
}

\author{
Athany Gutierres ${ }^{1}$ | Lattes | athany@gmail.com \\ Universidade Federal da Fronteira Sul
}

Felipe Flores Kupske² | Lattes | kupske@ufba.br

Universidade Federal da Bahia

Resumo: Partindo do pressuposto de que a teoria fonológica pode dialogar com o contexto educacional, este trabalho tem como objetivo principal apresentar e explicitar a relevância da gramática fonológica para o ensino de línguas adicionais, neste caso, o inglês. Para tanto, discutiremos dados de aquisição de aprendizes brasileiros de inglês (GUTIERRES, 2016) para o desenvolvimento da gramática da língua-alvo, analisados à luz da Teoria da Otimidade Estocástica (BOERSMA; HAYES, 2001). Os dados revelam que, na aprendizagem da nasal velar $[\mathrm{n}]$ das palavras terminadas com -ing em inglês, há alternância sistemática entre as nasais velar/velarizada e a palatal (variação), demonstrando a gradualidade que caracteriza a aquisição e a variabilidade que é inerente à aprendizagem de línguas. Dessa forma, há uma demanda para a atualização e o esclarecimento do conceito de gramática, buscando dissociá-la da unicidade da concepção tradicional que ignora a produção linguística do aprendiz e lhe apenas prescreve formas tidas como corretas de expressão.

Palavras-chave: Gramática fonológica; Linguística formal; Linguística aplicada ao ensino de inglês como língua adicional.

\footnotetext{
${ }^{1}$ Professora Adjunta de Língua Inglesa no Curso de Medicina da Universidade Federal da Fronteira Sul (UFFS), Campus Passo Fundo. Pesquisadora integrante do Laboratório de Ciências da Fala (LAFALA) da Universidade Federal da Bahia (UFBA)

${ }^{2}$ Professor Adjunto no Departamento de Letras Germânicas da UFBA. Pesquisador líder do LAFALA da UFBA.
} 
Abstract: From the assumption that phonological theory can dialogue with the educational context, this work has as its main objective to present and to explain the relevance of the phonological grammar for the teaching of additional languages, in this case, English. In order to do so, we discuss acquisitional data from Brazilian learners of English (GUTIERRES, 2016) for the development of the target language grammar, analyzed in the light of the Stochastic Optimality Theory (BOERSMA; HAYES, 2001). The data show in the learning of the nasal velar [ $\mathrm{y}$ ] of words that end in -ing in English, there is a systematic alternation between the velar / velarized and the palatal nasals (variation), demonstrating the gradualness that characterizes the acquisition and the variability that is inherent in language learning. Thus, there is a demand for the updating and clarification of the concept of grammar, seeking to dissociate it from the uniqueness of the traditional conception that ignores the linguistic production of the learner and only prescribes forms considered as correct expression.

Key-words: Phonological grammar; Formal linguistics; Applied linguistics to the teaching of English as an additional language.

\section{Introdução}

A ciência da linguagem avança a passos largos no que concerne ao surgimento de teorias que acomodem fenômenos fonológicos de naturezas distintas. Nesse sentido, apesar do "poder" consolidado de modelos gerativos, propostas que se afastam dessa tradição, como a Teoria de Exemplares ou a Fonologia de Laboratório ${ }^{3}$, por exemplo, emergem questionando paradigmas até então dominantes, tais quais a quebra da separação entre os níveis fonético e fonológico, a incorporação de aparato técnico-tecnológico às análises de fala, respaldando os estudos fonéticos, e até mesmo o questionamento sobre a própria especificidade da representação linguística.

Esse pós-modernismo ${ }^{4}$ na linguística não somente contesta alguns pressupostos tradicionais da fonologia, como remete a debates maiores, principalmente àqueles relacionados à integração desta com outras áreas do conhecimento, como a psicologia, a sociologia e a pedagogia. Particularmente em relação à última, nosso foco, a interface entre linguística teórica e aplicada, referente ao ensino, é uma possibilidade, não obrigatoriedade, como afirma Alves (2012, p. 241):

\footnotetext{
${ }^{3}$ Para uma caracterização dos modelos citados e de outros, ver Hora e Matzenauer (2017).

${ }^{4}$ Entendemos como pós-modernas as teorias pós-racionalistas, isto é, que se distanciam da hipótese de conhecimento apriorístico.
} 
[...] não precisamos 'forçar' um caráter aplicado em estudos cujos objetivos não são esses. Esta não explicitação não implica, entretanto, abdicar ou negar a valiosa contribuição que o entendimento do processo de aquisição, possibilitado por tais estudos, pode vir a dar para a pedagogia das línguas.

Apesar das divergências existentes entre teorias, um fato parece ser consensual à vasta maioria: a linguagem pressupõe um processamento cognitivo que pode ser representado. Ora, se os sons organizam-se de diferentes formas para constituírem unidades maiores e contrastam significados, são eles os elementos-base para a estruturação da gramática de uma língua que, dentre variadas possibilidades, serve à comunicação humana.

Nessa direção, nosso trabalho visa a esclarecer o conceito de gramática fonológica e explicitar sua relevância para o ensino, particularmente no contexto de inglês como língua adicional (LA $)^{5}$, valendo-se de um modelo teórico consolidado nos estudos linguísticos: a Teoria da Otimidade (PRINCE; SMOLENSKY, $2004[1993]^{6}$ ). Para tal, organizamos este artigo em quatro seções, além desta Introdução: (1) O que é gramática?, em que discorremos sobre as conceituações do termo, até chegarmos ao entendimento de gramática fonológica; (2) Gramática, aquisição e aprendizagem, em que discutimos a respeito do desenvolvimento da gramática fonológica como LA, com base no processo de aquisição e aprendizagem da nasal velar [n] em inglês em dados de -ing (GUTIERRES, 2016), analisados pela Teoria da Otimidade Estocástica (BOERSMA; HAYES, 2001); (3) Gramática fonológica e ensino, em que tratamos das implicações dos conhecimentos apresentados nas seções anteriores ao ensino de inglês-LA (particularmente ao ensino de aspectos fonético-fonológicos), e (4) Conclusão, em que fazemos o fechamento do texto, seguida das Referências.

Embora o presente texto direcione-se a um público-leitor abrangente de estudantes, pesquisadores e professores da área de Letras, dirigimos nossa redação especialmente àqueles professores de inglês que têm tido pouco ou nenhum contato com teorias linguísticas e/ou fonológicas recentemente; dessa forma, inclusive, nosso artigo contém

\footnotetext{
${ }^{5}$ Optamos pelo emprego do termo língua adicional (LA) seguindo concepções de Leffa e Irala (2014): a "outra" língua sendo aprendida alicerça-se na língua materna e no contexto de aprendizagem do aluno; serve aos próprios interesses do aprendiz, que podem ser locais ou globais; não tem por base os padrões de produção linguística de falantes nativos; concebe a aprendizagem como um direito individual com benefícios para a coletividade. Trata-se de uma nomenclatura que carrega consigo implicações epistemológicas e metodológicas, e, como este artigo estabelece uma interface teoria-ensino, consideramos adequado fazer tal escolha.

${ }^{6}$ Os anos indicados entre colchetes indicam a primeira edição das obras referenciadas.
} 
um número considerável de notas explicativas (de rodapé) e indicações de leituras. Para um leitor mais experiente, alguns conceitos explicitados podem parecer demasiado elementares. Longe de advogar um ou outro modelo teórico para a aquisição da linguagem, nosso objetivo é apresentar uma possibilidade de compreensão de como esse processo decorre na mente do aprendiz; e, neste momento, valemo-nos da Teoria da Otimidade Estocástica, que conjuga pressupostos de base gerativista a simulações computacionais. Ainda, tal hipótese, demonstrada empiricamente, reitera a importância do conhecimento teórico/fonológico para professores no âmbito da aprendizagem de inglês-LA, além de elucidar uma proposta que combina teoria, saber fundamental ao professor, e aplicação, a efetiva produção linguística dos aprendizes.

\section{0 que é gramática?}

Pode-se considerar três acepções distintas para o termo gramática: (i) uma vinculada à capacidade inata para a linguagem; (ii) uma de cunho metalinguístico, em que se fala sobre a língua, a partir de suas regras de produção; e (iii) outra relacionada ao ensino de línguas, de caráter disciplinar. Vemos que a mesma palavra pode ser entendida por meio de perspectivas (i) cognitivas, (ii) linguístico-analíticas e (iii) pedagógicas. Vamos tratar separadamente de cada uma delas.

\subsection{Gramática é capacidade linguística}

Quando nos comparamos a qualquer outra espécie viva na Terra, facilmente percebemos que somos os únicos dotados de uma complexa estrutura mental que processa e produz um sistema simbólico, que dentre múltiplas funções, serve à comunicação. Essa dotação biológica - a gramática - provém os indivíduos com a capacidade de articular sons com significados e transformá-los em linguagem. Foi a revolução cognitiva ${ }^{7}$ de Chomsky (2015 [1957], 1975 [1965]) que, partindo dos preceitos expostos, de base filosófica racionalista $^{8}$, alterou os rumos da linguística do século XX, cujo caráter puramente estrutural e descritivo passou a buscar uma compreensão orgânica da aquisição e do processamento das línguas naturais:

\footnotetext{
${ }^{7}$ De acordo com França, Ferrari e Maia (2016, p. 42-43), o marco da revolução cognitiva deu-se em 11 de setembro de 1956 em um Simpósio sobre Teoria da Informação realizado no MIT. "Nesse evento, Chomsky, Miller, Minsky, Newel e Simon apresentaram trabalhos e surpreenderam a todos pelo íntimo diálogo interdisciplinar que seus objetos de estudo ensejavam. A reunião prenunciava um momento de forte desenvolvimento para os estudos da mente e do cérebro.".

${ }^{8} \mathrm{O}$ racionalismo crê que a estrutura cognitiva é dada ao ser humano, é inata; "consiste em um conjunto de propostas - um procedimento, uma estratégia ou uma metodologia - para estudar a mente humana e a linguagem de maneira particular" (CHOMSKY, 2014, p. 17). Opõese ao empirismo, que afirma que a cognição é formada através da experiência e que todos os conhecimentos são compartilhados. Trataremos com mais detalhes sobre esse modo de pensamento na seção 1.2 .
} 
a teoria linguística é mentalista na medida em que tem como objetivo descobrir uma realidade mental subjacente ao comportamento efetivo [...] uma gramática de uma língua pretende ser uma descrição da competência intrínseca do falante-ouvinte (CHOMSKY, 1975 [1965], p. 84);

a gramática de uma dada língua deve mostrar como essas estruturas abstratas são concretizadas no caso dessa língua, ao passo que a teoria linguística deve esclarecer esses fundamentos da descrição gramatical e os métodos para avaliar e escolher entre gramáticas propostas (CHOMSKY, 2015 [1957], p. 150).

Nessa perspectiva, gramática é um saber intuitivo que falantes possuem sobre sua língua. Trata-se de um mecanismo interno que, por estar naturalmente disponível a todos os seres humanos, é universal. É o que Chomsky chamou de competência, um sistema de regras ou restrições disponível na mente/cérebro que governa a língua, não fazendo distinção se o falante-ouvinte é mais ou menos ou não escolarizado. É nesse sentido que a teoria gerativa assume um falante ideal: não aquele que fala perfeitamente seguindo as regras da variedade padrão, mas aquele que compartilha, de igual maneira, um órgão (cérebro) e um dispositivo (gramática) com capacidade gerativa de infinitas sentenças em dado sistema linguístico9.

Sob essa ótica, assume-se que nem tudo o que sabemos sobre uma língua é aprendido, mas já faz parte da competência ou da língua-I (do inglês, Internal language). A língua-I é ativada quando nosso dispositivo cerebral para a linguagem, a Gramática Universal (GU), entra em contato com estímulos linguísticos. Por essa razão, principalmente, a linguística gerativa não é considerada uma teoria de aprendizagem, e sim uma teoria gramatical associada às ciências naturais. Pensar na naturalidade com a qual as crianças aprendem a articular os sons de sua língua materna e os demais domínios do sistema sem qualquer instrução e a partir de estímulos fragmentados de seu ambiente social (Problema de Platão ${ }^{10}$ ), ou até mesmo considerar que aprendizes de uma língua adicional (salvo

\footnotetext{
9 Tal capacidade é referidade como uma propriedade universal a todos as línguas, conhecida como recursividade, uma operação que permite selecionar determinados objetos mentais e expandi-los (CHOMSKY, 2014, p. 30). Consideremos a frase "Maria gosta de João"; podemos introduzir sintagmas e expandir ad infinitum tal construção: "Maria gosta de João [que é meu vizinho]", ou "Maria [a cunhada da minha prima] gosta de João [que comprou um carro novo semana passada]".

${ }^{10} \mathrm{O}$ fato de o input linguístico que a criança recebe nos primeiros anos da infância não conter todas as informações linguísticas que essa criança, eventualmente, vai produzir (conhecido como "Pobreza de Estímulo") - o famoso "Problema de Platão" - remonta a um dos diálogos platônicos (Mênon) em que Sócrates tenta demonstrar que um escravo tem conhecimentos sofisticados de geometria sem jamais ter sido ensinado. O Problema de Platão faz essa analogia em relação à aquisição da linguagem: como a criança conhece os princípios que regem a sua língua, que não lhe são ensinados formalmente e nem estão disponíveis nos dados aos quais ela tem acesso? Para uma leitura orientada sobre este e outros argumentos da teoria gerativa de aquisição da linguagem, ver Grolla e Silva (2014), especialmente o capítulo 5.
} 
contextos de aquisição e individualidades de cada aprendiz) são capazes de adquirir certas propriedades linguísticas sem instrução explícita, além de fazer adivinhações criativas e inteligentes sobre o funcionamento da língua, são argumentos plausíveis para pressupor a existência de um módulo gramatical designado para a aquisição da linguagem. ${ }^{11}$

Desse modo, a noção de gramática como competência linguística, como vimos nesta seção, pode ser descrita formalmente através de regras, restrições ou outras formulações lógico-matemáticas que equiparam o processamento linguístico a um sistema computacional, como tem sido o trabalho de linguistas que seguem essa linha de investigação. Nesse sentido, a gramática é também formal, como veremos na próxima seção.

\subsection{Gramática é conhecimento formal}

A possibilidade de se considerar o estatuto formal da gramática originou-se na filosofia racionalista ${ }^{12}$ e está tradicionalmente atrelada à escola gerativa. Formal, nesse âmbito, diz respeito tanto (i) à organicidade da concepção de língua assumida por esses linguistas (seção anterior), quanto (ii) aos procedimentos de análise, descrição e adequação dos processos cognitivos, que podem ser explicados por meio de formulações matemáticas e lógicas computacionais.

Sendo a língua um sistema de base biológica, os gerativistas partem do pressuposto de que grande parte do conteúdo da mente humana é predisposto com o nascimento, incluindo-se a gramática. Disso decorre a premissa de que há uma porção particular nesse órgão - a faculdade da linguagem ${ }^{13}$ - destinada à aquisição, que é ativada a partir do momento em que a criança começa a receber input (dados linguísticos) em certa língua. A esses preceitos opõem-se os empiristas/externalistas, para quem o conteúdo da mente advém da experiência comum, e a aquisição da linguagem dá-se da mesma forma e conco-

\footnotetext{
${ }^{11}$ Além disso, por acreditar no inatismo da gramática, na concepção de língua como uma estrutura computacional materializada na mente/cérebro, e na assunção de que a única forma de desvendar a natureza da linguagem é isolá-la de fatores contextuais, é que o gerativismo também vem sendo chamado de Biolinguística. Para saber mais, ver Cerqueira e Mariano (2016).

${ }^{12}$ Os racionalistas modernos (de Descartes a Wittgenstein, séculos XVII a XX) adotaram a matemática para trabalhar com a ideia de razão e explicar a realidade. Foram eles os introdutores do método científico-dedutivo, postulando que algo é verdadeiro somente se pode ser verificado, e que énecessário fragmentar o todo para se analisar as partes com mais profundidade (Gasparetto Junior, s/a).

${ }^{13}$ Chomsky (2014, p. 69) compara a faculdade da linguagem ao sistema digestivo humano: um órgão que processa e produz algo. Mantém a distinção entre "faculdade da linguagem ampla" e "faculdade da linguagem estreita", sendo a primeira qualquer coisa que conecte o que é processado e o que é produzido, e a segunda, o mecanismo que "produz a variedade infinita de expressões que fornecem informações usadas por essas duas interfaces" (princípio da recursividade; ver nota 4).
} 
mitantemente a outros tipos de desenvolvimento de ordem geral. Para eles, é o ambiente que fornece todos os padrões a serem seguidos e categorizados como gramática, assim, ao contrário do conhecimento a priori - como defendido pelos gerativistas, pensa-se na aquisição como um processo a posteriori, isto é, não prevendo conhecimento inato.

Dois argumentos devem ser destacados no que tange à rejeição do aspecto social ao estudo da mente. Em primeiro lugar, para Chomsky (2014, p. 26), em mais de $90 \%$ do tempo, usamos a linguagem como atividade interna e individual: pensamos nas tarefas do dia a dia, organizamos nossa agenda, lemos etc. Em segundo lugar, é importante explicar que Chomsky não nega que uma das funções da linguagem seja a comunicação (embora, para ele, não a principal), mas tal afirmativa implica um entendimento menos superficial do que é, de fato, comunicação, já que podemos comunicar através do nosso estilo de cabelo ou vestuário, por exemplo.

A especificidade da língua, do ponto de vista chomskiano, serve a propósitos internos, apenas; no escopo da comunicação, interessa o que a mente/cérebro processa e produz, e para ali - os demais fatores que incidem sobre a fala ou a escrita, depois de produzidas, são matéria de análise de "outras linguísticas”. Reiterando tal argumento, Grolla e Silva (2014, p. 82) pontuam que

[... a visão social da linguagem é muito forte na nossa cultura e nos faz pensar que as propriedades últimas que as línguas humanas têm dependem fundamentalmente de elas serem usadas para o que são, isto é, para a comunicação. [... ] as línguas humanas têm as propriedades que têm porque nós somos o bicho homem e o nosso código genético é tal que determina um conjunto específico de características para as línguas naturais, e não outro.

Como dissemos, a matemática está historicamente associada ao modo racional de pensar. Os racionalistas acreditam que, quando se dispõe de pouca evidência para explicar um fato, ou de diferentes hipóteses para explicar a mesma evidência, deve-se adotar a explicação mais simples (Navalha de $\mathrm{Occam}^{14}$ ). Nesse sentido, diante das diversas hipóteses sobre a aquisição e o processamento linguístico, essa explicação seria a de que a aritmética, uma ciência lógica, é uma ramificação da linguagem. A simplicidade das ciências exatas reside na proposição de uma formulação ou regra geral para explicar os processos naturais. Na linguagem, a universalização estaria presente na GU (princípios), e as regras

${ }^{14}$ Embora esse princípio tenha ganhado popularidade a partir do filósofo inglês William de Occam (1285-1347), Aristóteles já o aplicava no século IV a.C. 
particulares de cada língua seriam adquiridas a partir da exposição ao ambiente (parâmetros $)^{15}$.

A matematização na linguística é uma possibilidade de explicar o funcionamento da língua. Tal formalização foi introduzida na área por Chomsky (2015 [1957], p. 117) no início de sua teoria linguística, que já se propunha a fornecer um procedimento de avaliação de gramáticas, que consistia em uma parte sintagmática e uma parte transformacional, de onde são geradas sentenças simples (ativas e declarativas) da língua (no caso, o inglês), e cujas demais sentenças produzidas infinitamente são desse núcleo todas derivadas, "transformadas". ${ }^{16}$

Atualmente, modelos derivados do gerativismo padrão, como a Teoria da Otimidade (do inglês, Optimality Theory) (TO) Estocástica (BOERSMA; HAYES, 2001), por exemplo, utilizam programas computacionais para simular a aquisição de línguas e são capazes, inclusive, de formalizar a variação linguística, característica presente em todas as línguas naturais que, por muito tempo, foi um problema manifesto para o paradigma. A formalização que apresentaremos na seção 2.1 trata de uma hipótese de representação do inglês sendo adquirido e aprendido por falantes sul-brasileiros, pela TO Estocástica. O modelo, por sua vez, pode ser analogamente comparado aos componentes da GU, responsáveis pela produção da fala. É como se pudéssemos visualizar o que acontece na mente do aprendiz durante a aquisição de novas formas linguísticas.

Até o momento, estamos familiarizados com as concepções integradas de gramática como um sistema orgânico, inato e biológico, e gramática como um sistema lógico-formal, em que operações matemáticas são análogas ao processamento linguístico. Passaremos agora, na seção 1.3, à noção externa mais difundida de gramática, aquela que diz respeito às regras da língua, e que o ensino tradicionalmente prescreve como a forma mais adequada de expressão linguística.

${ }^{15}$ Grosso modo, a Teoria de Princípios e Parâmetros (P\&P) estabelece princípios universais (comuns a todas as línguas) e parâmetros específicos (particulares a cada sistema). Essa teoria dá conta da regularidade universal das línguas e da variação encontrada em cada sistema. Um exemplo de princípio é que toda a língua possui sujeito. Contudo, algumas línguas, como o português, podem omitir o sujeito enquanto outras, a exemplo o inglês, não. $\mathrm{O}$ que diferencia essas duas língua é, então, o Parâmetro do Sujeito Nulo.

${ }^{16}$ A gramática gerativo-transformacional é a teoria inicial de todo trabalho teórico de Chomsky, que vem se aperfeiçoando ao longo do tempo. Aspects (1965) é tida como a teoria padrão, seguida pela Teoria de Regência e Ligação (1981), a teoria padrão estendida, e pelo Programa Minimalista (1996) (cf. Harris apud Othero; Menuzzi in Chomsky 2015 [1957], p. 27). Neste artigo, abstemo-nos de apresentar as formalizações matemáticas de tais modelos, por duas razões: primeiro, porque dizem mais respeito à sintaxe do que a fonologia; depois, porque fogem ao escopo deste trabalho que, apesar de apresentar conceitos teóricos fundamentais à fonologia contemporânea, focaliza uma interface com o ensino de línguas. 


\subsection{Gramática é disciplina escolar}

Para Moura Neves (2002), a história da organização gramatical no Ocidente vai da universalidade dos filósofos à particularização dos gramáticos; da teorização ao conhecimento empírico; da abstração à análise superficial. A gramática como busca do mecanismo interno da língua precedeu a noção de gramática descritiva com vistas à prescrição que, por sua vez, surgiu com a função de transmitir a literatura grega, evidenciando, em sua origem, a educação linguística como um ato marcadamente elitizado.

Temos, na história gramatical, três domínios distintos que espelham, em alguma medida, as concepções de gramática tratadas aqui: (i) o dos filósofos, que buscavam a verdade ou a natureza das coisas através da linguagem, a essência do homem; (ii) o dos sofistas, que ensinavam política aos homens, buscando eficiência na comunicação para a persuasão; e (iii) o dos gramáticos, que buscavam preservar e disciplinar o uso linguístico. Todos movimentaram-se em relação à língua através do elo que é estabelecido entre uma cadeira sonora emitida (som) e o sentido produzido por essa sequência (significado).

Conforme mencionamos, foi na época helênica que surgiram as primeiras gramáticas, manuais do bom uso da linguagem. O objetivo era transmitir padrões linguísticos da escrita literária considerados superiores, e que drasticamente contrastavam com a língua vulgar falada no dia a dia, repleta de barbarismos. Representativa desse período foi a gramática de Dionísio o Trácio, editada pela primeira vez em 1715 (MOURA NEVES, 2002, p. 51).

Historicamente, a gramática como disciplina (escolar) disciplina os usuários da língua a empregar formas dadas como as corretas e mais adequadas, baseadas em uma variedade linguística que é tida como a padrão e que normalmente apoia-se em uma obra didática de referência. Como se percebe, esse entendimento de gramática, seja ele o ensino de regras, ou o livro que prescreve tais regras, nada relaciona-se com a ideia de competência; aliás, a disciplina, como exposta aqui, nega a competência do aprendiz, uma vez que sua produção linguística sempre poderá ser "consertada” ou substituída por escolhas mais apropriadas, independentemente do contexto de uso.

Como um exemplo, observemos as orientações introdutórias de uma gramática contemporânea do inglês, destinadas a estudantes não nativos:

(1) Este livro é um guia de referência prático para questões desse tipo [previamente exemplificadas]. Ele lida com mais de 600 tópicos que geralmente causam problemas a estudantes estrangeiros de inglês. A maioria dos tópicos abordados são gramaticais, mas há também 
explicações de um considerável número de problemas comuns de vocabulário. (SWAN, 2003, p. xi.). ${ }^{17}$

Sobre o seguimento de uma norma padrão da qual as regras são derivadas, cita-se: "As explicações lidam principalmente com o inglês britânico moderno padrão [... Diversas informações são dadas sobre usos do inglês americano, mas este livro não se trata de um guia sistemático para o inglês americano ${ }^{18 ”}$ (SWAN, 2003, p. xii).

Apesar dos quatro séculos que nos distanciam dos alexandrinos, alguns ambientes de ensino ainda promovem a ideia de gramática como apenas o uso correto da língua-alvo, fortemente influenciados pelo uso do livro didático. Embora as abordagens comunicativas para o ensino de línguas tenham despontado na década de 1980, influenciadas pelo conceito de competência comunicativa de Hymes (1972), muitos professores têm dificuldades de situar o ensino de gramática (fonológica, morfológica ou sintática) em suas práticas didáticas, se é que gramática deve ser ensinada. Deixemos, por ora, a interface gramática (fonológica)-ensino para ser discutida na seção 3.

Gramática pode, então, ser uma abstração (1.1), uma formalização dessa abstração (1.2), ou um sistema de regras a ser seguido e ensinado (1.3). A breve teorização que fizemos acerca do conceito de gramática pretende esclarecer a diversidade de domínios teóricos sobre a qual essa noção circula na linguística, além de estabelecer um contexto para o que entendemos de gramática fonológica, seguindo Matzenauer (2015): uma entidade abstrata (competência) que contém representações fonológicas e relações entre as unidades da língua, efetivando a comunicação entre os falantes. Vemos que a percepção da autora envolve, ao mesmo tempo, uma suposição representacional da fonologia e uma realização físico-funcional, dado seu uso.

Desse modo, quando tratamos de gramática nesse texto, referimo-nos, sim, às representações mentais intrínsecas anteriores à produção da fala (por se tratar de fala, é fonológica). A partir de nosso papel como linguistas e professores, a problematização que fazemos é a seguinte:

se a gramática fonológica é inerente aos indivíduos, e a sociedade moderna dispõe de incontáveis meios de acesso e autoaprendizagem de línguas adicionais, principalmen-

17 Esta e as demais traduções são de nossa responsabilidade. Do original: "This book is a practical reference guide to questions of this kind. It deals with over 600 points which regularly cause problems for foreign students of English. Most of the points treated are grammatical, but there are also explanations of a certain number of common vocabulary problems...

18 "The explanations deal mainly with standard modern British English [... ] A good deal of information is given about American usage, but the book is not intended as a systematic guide to American English.”. 
te o inglês, qual o papel do ensino no processo de aprendizagem da fala na língua-alvo? se ensinamos regras estruturais da língua (gramática sintática), e regras de estrutura e formação de palavras (gramática morfológica), domínios mais diretamente relacionados ao registro escrito, [como] devemos tratar a gramática fonológica que, no nível superficial, transforma-se em fonética (pronúncia)?

se acreditamos na fonologia como competência, mas também assumimos a relevância da mediação didática no processo de aprendizagem de inglês-LA, como aliar com coerência preceitos distintos de gramática para o mesmo fim? Como dialogam os conceitos de aquisição (natural) e aprendizagem (mediada)?

São essas as questões que orientam nossa discussão, e sobre as quais discorreremos ao longo do texto, mais especificamente ao final do artigo. A próxima seção apresenta uma análise de dados de aquisição e aprendizagem da nasal velar em inglês em palavras terminadas por -ing, que balizará nossa argumentação.

\section{Gramática, aquisição e aprendizagem}

Existe, nas diferentes facetas da linguística, notável variação terminológica, a exemplo do termo gramática, que pode evocar, como vimos, três concepções distintas. Debate similar ocorre entre aquisição e aprendizagem: alguns linguistas afirmam haver diferenças entre os termos, filiados a determinadas correntes teóricas; outros, usam o primeiro ou o segundo intercambiavelmente. Neste trabalho, em consonância com o paradigma adotado, optamos por referir aquisição como o processo natural de adquirir uma língua (gramática como competência), e aprendizagem, como o processo de refletir metalinguisticamente sobre sua produção e estar submetido a situações de instrução explícita (gramática como formalização e ensino) ${ }^{19}$.

Os dados que discutiremos dizem respeito ao processo de aquisição e aprendizagem da nasal velar em palavras terminadas por -ing, sufixadas (doing, "fazendo"; verbo "do" + sufixo modo-temporal "ing") ou não (morning, "manhã", em que o -ing faz parte do radical da palavra, sendo impossível separar "morn" de "ing”). Mais uma vez: dizemos aquisição $e$ aprendizagem, pois assumimos que os falantes-aprendizes dispõem de um mecanismo natural para o domínio linguístico, além de serem, na época da coleta dos da-

\footnotetext{
${ }^{19}$ Essa distinção é baseada naquela feita por Krashen (2009 [1982]) em seu modelo de aquisição de segundas línguas chamado Monitor Model, inspirado na teoria de Chomsky para a aquisição de línguas maternas. Tal distinção remeteria, por consequência, à diferenciação entre segunda língua (L2) e língua estrangeira (LE). Entretanto, desconsideramos esse binômio porque já nos posicionamos em relação ao emprego do termo "língua adicional" (LA), que pode associar a compreensão de aquisição e aprendizagem tal qual entendemos.
} 
dos (2014), estudantes do Programa de Línguas Estrangeiras (PLE) da Universidade de Caxias do Sul (UCS). Os dados foram coletados através da gravação de conversas semiespontâneas baseadas em tarefas pré-elicitadas (de modo a incitar a produção das nasais em final de palavra), realizadas por dez aprendizes de inglês, totalizando um tempo total de vinte horas de gravação. Foram selecionados pouco mais de 500 vocábulos terminados por -ing, compondo o corpus total da pesquisa. Tais dados foram analisados também sociolinguisticamente, controlados por variáveis sociais e estruturais ${ }^{20}$.

Todavia, duas colocações a respeito dessa produção linguística são necessárias: (i) o caráter semiespontâneo das conversas gravadas aproxima-se da fala "natural" desses falantes de inglês-LA em contexto de aprendizagem; (ii) os dados apresentaram variação no percurso da coleta, entre uma nasal velarizada ${ }^{21}$, produção assemelhada à nativa (looki[n], "olhando"), e uma nasal palatal, coarticulada com a vogal anterior precedente [i], produção fonética natural do português brasileiro (looki[n]) (a tentativa de falar uma consoante nasal final, no processo de aquisição, está associada à articulação intencional do falante-aprendiz em direção à aprendizagem de um fonema inexistente em sua língua materna).

Primeiramente, apresentaremos a teoria de base da aquisição - a Teoria da Otimidade Estocástica (BOERMSA; HAYES, 2001) -, modelo que formalizou a gramática fonológica variável do processo de aquisição e aprendizagem em questão. Na sequência, argumentaremos como a formalização proposta explica com adequação a fala dos aprendizes, resultado de representações fonológicas subjacentes associadas a fatores externos relativos ao espaço social (sala de aula) em que a língua é praticada.

\footnotetext{
${ }^{20}$ Para acessar o estudo completo, ver a tese de Gutierres (2016).

21 "Velarizada" pois os dados foram submetidos à análise fonológica (de oitiva), e não fonética. Tal análise justifica-se pela preponderância da percepção do professor em relação à fala de seus estudantes ante à definição precisa do tipo de nasal produzida, que pode ser verificada por análise acústica. Para aprendizes brasileiros de inglês-LA, a realização acurada da nasal velar é articulatoriamente complexa, já que eles precisam conjugar, sequencialmente, a produção de um traço vocálico [+anterior] à de um traço consonantal [+posterior] ([iN]). Na produção interlinguística, há a intenção de se produzir uma nasal em coda, já que esta, na língua-alvo (inglês) é fonema, contrasta significados (su[m] "soma", su[n] "sol" e su[n] "cantado"); já em português, língua materna dos falantes, a nasal velar não é fonema pertencente ao inventário da língua; é realização fonética que se realiza coarticuladamente com a vogal anterior, conforme afirmam Freitas e Neiva (2006, p. 10): "A consoante nasal em coda silábica não se realiza, pois, do ponto de vista fonético, esta consoante é eliminada após transmitir o traço nasal para a vogal precedente, que fica mais longa."
} 


\subsection{Teoria da otimidade Estocástica}

A TO Estocástica (BOERSMA; HAYES, 2001) opera sob os mesmos princípios da TO clássica 22 (PRINCE; SMOLENSKY, 2004 [1993]): formaliza gramáticas através do mapeamento entre input e output, entre o que está na mente/cérebro e o que o falante efetivamente diz, que é operado pelos componentes da $\mathrm{GU}^{23}$ : o dispositivo GEN cria diferentes candidatos a output (Out1, Out2,...), que são avaliados por EVAL com base num conjunto CON de restrições (Outi $1 \leq \mathrm{i} \leq \infty$ ) hierarquicamente dispostas da esquerda para a direita. Dessa avaliação, emerge a forma "ótima" (Outreal), que se manifesta na fala do indivíduo como derivação fonética. Em outras palavras: há um mecanismo, inerente ao cérebro humano, que gera diferentes possibilidades de dizermos uma palavra (GEN); GEN produz essas possibilidades, chamadas, nessa teoria, de "candidatos"; outro componente (EVAL) avalia os candidatos com base em restrições que afirmam o que a língua pode e não pode fazer - essas restrições têm graus de importância distintos, com base em "regras" que podem ser mais ou menos seriamente violadas em determinada língua; cruzando-se candidatos a formas de fala e restrições linguísticas, tem-se um candidato vencedor, a forma "ótima" (daí o nome Teoria da OTIMidade).

Figura 1. Processamento gramatical na TO

$$
\begin{aligned}
& \text { Structure of Optimality-theoretic Grammar } \\
& \text { a. Gen } \left.\left(\mathrm{In}_{\mathrm{k}}\right) \quad \rightarrow \text { Out }_{1}, \mathrm{Out}_{2}, \ldots\right\} \\
& \text { b. H-eval (Outi, } 1 \leq \mathrm{i} \leq \infty) \rightarrow \text { Out }_{\text {real }}
\end{aligned}
$$

Fonte: Prince e Smolensky (2004 [1993], p. 05).

A principal diferença entre o modelo padrão e sua versão estocástica é que o primeiro foi desenhado para dar conta de outputs categóricos (uma forma de saída, uma única possibilidade de fala), enquanto que o segundo consegue explicar a realização de mais de um output, correspondente à variação naturalmente encontrada na fala (um mesmo in-

${ }^{22}$ Recomendamos a leitura do texto proponente da teoria (PRINCE; SMOLENSKY 2004 [1993]), ou, para um leitor mais principiante, sugerimos Bisol e Schwindt (2010) e, ainda, a resenha deste (ULRICH, 2017).

${ }^{23}$ A saber: CON (CONstraints), o conjunto universal de restrições linguísticas, que estabelecem o que é permitido ou não em cada sistema linguístico; GEN (GENerator), o constituinte que gera candidatos a output, correspondente às infinitas possibilidades de fala, e EVAL (EVALuation), o constituinte que avalia esses candidatos, com base em CON; além de componentes particulares da língua do falante, como o LEXICON, que contém as representações fonológicas e informações morfológicas dos itens lexicais, além da hierarquia de CON. 
divíduo pode falar a mesma palavra de maneiras foneticamente distintas). A representação gramatical, correspondente ao processamento mental da fala, também é diferente nas duas propostas: a TO clássica apresenta tabelas (tableaux); a TO Estocástica, uma escala contínua, em que as restrições recebem pesos numéricos. É a partir desses tableaux ou dos pesos na escala que as restrições expressam sua hierarquia de importância na língua. É importante ressaltar que as restrições são universais, isto é, existem em todas as línguas, e é justamente a sua disposição hierárquica, da esquerda para a direita nos tableaux, ou em termos numéricos na escala, que determina a gramática responsável pela produção de determinada(s) forma(s) linguística(s).

A TO Estocástica recebe esse nome, pois o algoritmo vinculado ao modelo, o Algoritmo de Aprendizagem Gradual (do inglês, Gradual Learning Algorithm, ou GLA ${ }^{24}$ ), é de natureza estocástica: lida com processos probabilísticos, não aleatórios e é afetado por um valor de ruído estatístico a cada avaliação (momento de fala) de candidatos. Em termos de linguagem, executa uma matemática que reflete probabilidades de fala, calculadas de acordo com algumas configurações padrão do GLA e com os dados carregados pelo linguista/analista. ${ }^{25} \mathrm{O}$ algoritmo pressupõe que, se o aprendiz tem acesso a um inventário fonológico de restrições universais, então, existe a possibilidade de que qualquer gramática seja aprendida (considerando-se novos ordenamentos de restrições), dada a existência de um mecanismo disponível que ranqueie as restrições com base no input (BOERSMA; HAYES, 2001).

A proposta de Boersma e Hayes (2001) nada mais é do que um programa computacional representativo do trabalho da GU na mente dos falantes; de modo bastante simples mas ilustrativo, é como se nossa mente/cérebro fosse uma máquina que produz fala. Assim, adquirir uma língua nessa perspectiva é promover ou demover restrições linguísticas dispostas abstrata e hierarquicamente em uma escala contínua, em que o estado atual da gramática do aprendiz é gradualmente confrontado com a evidência positiva (dados de input do ambiente). A aproximação dos valores numéricos de cada restrição, como veremos a seguir, é representativa das possibilidades de variação linguística.

Os dados obtidos por Gutierres (2016) revelam que, no processo de aquisição e aprendizagem da nasal velar $[\eta]$ das palavras terminadas com -ing em inglês, há alternância sistemática entre as nasais velar/velarizada e a palatal (variação). Mostraremos apenas um dos momentos iniciais de fala/avaliação gramatical gerados pelo GLA, em que o

${ }^{24}$ É comumente operado através do programa computacional Praat (BOERSMA; WEENINK, 2017).

${ }^{25}$ Para uma explanação didática e detalhada do algoritmo, ver Alves (2017). A nomenclatura em português para a terminologia empregada na análise feita com o GLA é baseada nesta publicação. 
aprendiz produz um dado (palavra com -ing) com a nasal palatal. O GLA gera a seguinte tabela:

Figura 2. Valores de ranqueamento e desarmonia (palatal)

$\begin{array}{cccc} & \text { ranking value } & \text { disharmony } & \text { plasticity } \\ \text { NoStopCoda } & 100.000 & 98.609 & 1.000000 \\ \text { AgreePlaceVN } & 50.447 & 51.420 & 1.000000 \\ \text { IdentNasal } & 49.553 & 45.856 & 1.000000 \\ \text { Dep } & 0 & 1.777 & 1.000000\end{array}$

Fonte: Gutierres (2016, p. 159).

Na Figura 2, os nomes em negrito e em azul correspondem às restrições linguísticas. As restrições linguísticas são imperativos que ditam o que é proibido em cada sistema linguístico. Na gramática fonológica que estamos analisando, restrições da língua materna (português) e da língua adicional (inglês) estão interagindo na mente do aprendiz, representando a gramática em aquisição. São elas: NoStopCoda: consoantes plosivas são proibidas em coda (final de palavras); AgreePlaceVN: vogal e consoante nasal seguinte precisam compartilhar o mesmo ponto de articulação; IdentNasal: a consoante nasal do input (representação mental) precisa ser idêntica à do output (produção no nível da fala); Dep: não insira segmentos no output.

Cada restrição recebe um valor numérico atribuído pelo programa computacional, com base nos dados a eles informados pelo linguista (que advêm das gravações das conversas dos aprendizes, nosso corpus de análise). Esses valores são valores que identificam as restrições, e estão presentes na coluna ranking value: a restrição NoStopCoda é a mais alta na hierarquia (valor $100^{26}$ ), a "mais importante” na gramática em aquisição; a restrição Dep é a mais baixa (valor 0), a "menos importante" na gramática; as outras duas restrições possuem valores intermediários (50 e 49, respectivamente) e, como veremos em breve, serão as mais relevantes para explicar a fala variável dos aprendizes.

A cada momento de fala (no software, equivalente a cada dado/palavra com nasal final) o valor da restrição (da coluna ranking value) é alterado, e esse novo valor aparece na coluna disharmony: a restrição NoStopCoda, cujo valor de restrição é 100, alterou-se para 98 quando o primeiro dado foi avaliado, por exemplo. Disharmony é o que chamamos de ponto de seleção. Os valores dessa coluna no algoritmo sempre serão alterados, confome os diferentes momentos de fala dos aprendizes e dadas as condições pré-estabelecidas

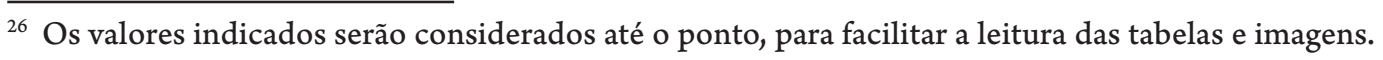


pelo programa (valores default de ruído e plasticidade), que podem ser entendidas como as variáveis externas que incidem sobre o processo de aprendizagem de uma língua adicional. Essa variação de valores movimenta-se dentro de um limite de 5 pontos para mais ou para menos (em uma representação em uma escala contínua, como na da Figura 3 a seguir, 5 pontos para a esquerda ou para a direita); assim, por exemplo, o ponto de seleção (disharmony) da restrição Dep pode atingir no mínimo o valor de -5 e no máximo o valor de 5 .

Observemos como essa representação se estabelece em uma escala contínua:

Figura 3. Gramática da nasal (palatal)

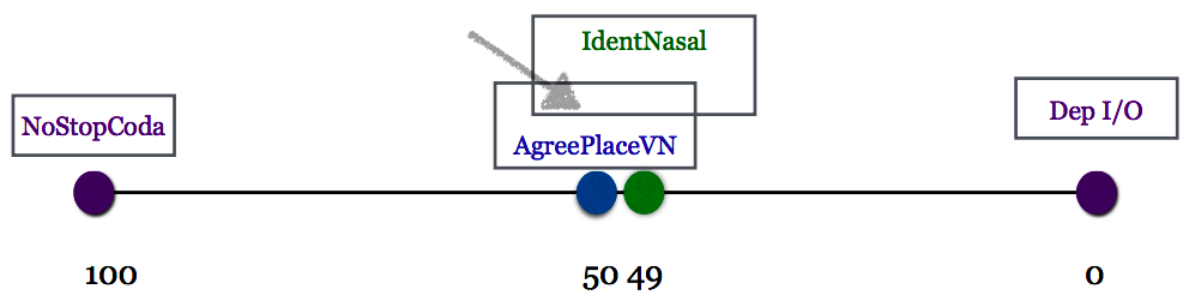

Fonte: Gutierres (2016, p. 159).

Os pontos indicam os valores de ranqueamento/centrais (ranking value) de cada restrição; as quatro áreas retangulares indicam as possibilidades de variação dos valores de seleção (disharmony), em termos de valores máximos e mínimos que cada restrição pode atingir: NoStopCoda (105-95), AgreePlaceVN (55-45), IdentNasal (54-44) e Dep I/O (5 e -5). No GLA, uma informação é fundamental: se a distância do valor de seleção (disharmony) entre duas restrições for menor que 10 (como é o caso de IdentNasal e AgreePlaceVN, em que essa diferença é apenas 1, = 50-49), haverá sobreposição de valores das restrições, como indicado pela flecha cinza na área sobreposta. Tal área comum de abrangência significa que (i) essas serão as restrições mais atuantes/ativas na aquisição da gramática dos aprendizes, e (ii) elas serão responsáveis pela variação encontrada na fala analisada. Decorrente de (i) é o fato de que, ora o aprendiz vai produzir a nasal velarizada - correpondente à representação-alvo da aprendizagem (a nasal velar, fonema do inglês) - quando IdentNasal tiver um valor maior que AgreePlaceVN; e ora vai produzir uma nasal palatalizada - aproximada da gramática de sua língua materna - quando AgreePlaceVN obtiver um valor maior que a restrição IdentNasal, já que esta pressupõe correspondência entre a nasal que é pronunciada e aquela que está supostamente na representação mental, e aquela $($ AgreePlaceVN) indica que a vogal ([i]) e nasal seguinte 
precisam ter o mesmo ponto de articulação, fazendo com que a consoante produzida seja anterior/palatal. No momento de fala em análise, a nasal realizada foi a palatal, já que a restrição AgreePlaceVN atingiu um valor de seleção (disharmony) superior a IdentNasal (veja Figura 2), indicando que, neste momento de fala, a gramática sendo adquirida atribui maior relevância à concordância de ponto de articulação na produção dos segmentos vocálico e nasal finais da palavra, em detrimento à obediência da identidade de traços da consoante nasal entre a representação e a produção linguística. Aparentemente, as restrições localizadas nos extremos dessa escala não apresentam pesos próximos o suficiente para influenciarem na variação observada, tampouco para gerarem outras formas de realização da nasal, além das observadas, em coda silábica final.

A TO Estocástica, através do GLA, demonstra a gradualidade que caracteriza a aquisição e a variabilidade que é inerente à aprendizagem. Trata-se, portanto, de um modelo que associa noções de gramática fonológica e aprendizagem, a interface teórico-gramatical e as possíveis situações de aprendizagem. A esse respeito, discutiremos na próxima seção.

\section{Gramática fonológica e ensino}

Apresentar a variabilidade semântica do termo gramática - restringindo-o ao uso da fonologia - e associar tais noções a um contexto pedagógico implica a compreensão de uma interdependência conceitual entre gramáticas. Pressupondo-se uma hipótese biológica universal para a linguagem, em que os indivíduos começam a falar, sob condições mínimas, porque estão programados para isso, é inegável que a aquisição fonológica de uma língua pressuponha a aquisição de uma gramática, um conjunto de sons estruturados. Entretanto, quando pensamos sobre questões de ensino de línguas adicionais, sustentar-se por teorias aquisicionistas-internalistas, apenas, não é suficiente para compreender e poder intervir, de forma apropriada, na aprendizagem.

Entendemos que o processamento de aquisição de língua materna e língua adicional envolve mecanismos distintos - um ocorre naturalmente nos primeiros anos de vida; o outro pode ocorrer na idade adulta, quando uma gramática já está estruturada na mente/cérebro; sabemos, por observação e por acesso científico (ALVES, 2013; GASS; SELINKER, 2008; HAHN, 2010; GARCIA, 2012; GUZZO; GUTIERRES, 2013; ALVES; LUCENA, 2014; GUTIERRES, 2016; AZEVEDO, 2011, 2016), da influência da língua materna sobre a adicional; é possível também presumirmos a presença da GU no processo de aquisição e aprendizagem da LA (WHITE, 1981, 2005; GREGG, 1989; 
SELINKER, 1996; MOHANAN; MOHANAN, 2003; MATZENAUER; AZEVEDO, 2016), embora haja controvérsias a esse respeito. Além dos fatores internos ao processo de aquisição, estamos também cientes, como professores, que os espaços sociais de uso de LA em contexto brasileiro impõem limites à aprendizagem: poucas horas de contato com a língua, input limitado, professores deficientemente qualificados, grande número de aprendizes em um mesmo ambiente, pouca prática efetiva da língua, além de fatores individuais de cada aprendiz.

No que diz respeito à fonologia, a atualização do conceito de gramática implica não apenas conhecer as suas dimensões, mas dissociá-la da unicidade da concepção tradicional à qual está envolta: aquela que ignora a produção linguística do aprendiz e lhe prescreve formas corretas de expressão. Entender que o aprendiz tem uma gramática (no caso de um aprendiz de LA, mais de uma gramática) é o primeiro passo para entender que a língua em aprendizagem é variável, que o processo desenvolvimental não é linear e que, ainda, em termos de aprendizagem, a internacionalização do inglês como língua franca (JENKINS, 2006; MAURANEN, 2018) destituiu o poder hegemônico de variedades tidas como standards, como o inglês americano ou britânico. A tendência global contemporânea - no que diz respeito à aprendizagem de línguas adicionais - parece caminhar em direção à democratização e à valorização da identidade estrangeira (desde que seja mantida a inteligibilidade comunicacional), amparada cientificamente. Desse modo, precisamos admitir a gramática como competência no sentido de acolher a capacidade produtiva do falante, separando-a da noção de erro. $\mathrm{O}$ modelamento da aquisição da nasal velar pela TO Estocástica (como explicitamos na seção anterior) é coerente com essa linha de raciocínio: a forma "desviante" da padrão (a nasal palatal, aquela que pode se realizar naturalmente no final das palavras em português, coarticulada com a nasalização da vogal precedente) é vista como uma forma "ótima" produzida pelo aprendiz - mesmo sendo uma produção divergente daquela de um falante nativo - advinda de restrições fonológicas atuantes em sua língua materna, parte de seu desenvolvimento gramatical em direção à aprendizagem da língua-alvo.

No tocante à fonética, julgamos que a pronúncia deve ser abordada de forma integrada a outros conhecimentos e habilidades linguísticas, merecendo um tratamento direcionado às necessidades do aprendiz (evidenciadas pela fala) e aos objetivos da aprendizagem (ALVES, 2012a). É tarefa do professor acolher a produção linguística dos aprendizes, ofertar variedade de input auditivo, propiciar ao aprendiz a autorreflexão sobre sua própria fala e planejar abordagens mediadoras que não desencorajem-no em seu 
processo de aprendizagem, mas que também mostrem-lhe alternativas linguísticas mais apropriadas do que a produzida, se este for o caso. Cabe a ressalva de que, uma vez considerada a existência da GU e de seu acesso (direto, indireto, parcial ou total) ${ }^{27}$ na aquisição de LAs, assume-se que a produção do aprendiz não viola princípios universais ali presentes, e nem deve ser considerada como um erro, dados os limites de inteligibilidade. A TO Estocástica, através do modelamento da aquisição fonológica apresentado, constitui-se como uma evidência científica que justifica a produção linguística do aprendiz e propõe um redirecionamento do olhar do professor na proposta de práticas pedagógicas mais significativas.

Nosso argumento é favorável ao ensino de pronúncia, cuja necessidade perpassa a instrução segmental (fonemas) e avança para questões suprassegmentais (sílabas, ritmo, entonação, acento), estando de acordo com pesquisas recentes (ALVES; BAUER, 2011, 2013; ALVES, 2012, 2015; CRISTÓFARO-SILVA; YEHIA, 2013; KUPSKE, 2015; KUPSKE; ALVES, 2017), que têm demonstrado os benefícios da instrução explícita formal para o aperfeiçoamento da fala em LA. Ademais, estamos atentos ao fato de que debates acerca do ensino relacionam-se, sobretudo, à formação de professores nas universidades, cuja discussão não cabe no presente texto; muito brevemente, a problemática que levantamos sobre as facetas da gramática sob uma perspectiva formal e sua possível relação com o ensino de línguas é coerentemente sintetizada por Moura Neves (2002, p. 23) e também por Alves (2012b, p. 238; 246), respectivamente:

E a pergunta é esta: o que se tem feito, nas universidades, para que o professor $[\ldots]$ consiga minimamente equacionar a questão da relação básica entre língua e gramática e, decorrentemente, para que ele possa entender qual é o estatuto do usuário da língua?

Para a interação entre as formas de conhecimento prático e teórico, é necessário estabelecer o elo entre pesquisa e ensino. Dessa forma, a formação do pesquisador, em nível de pós-graduação, é fundamental. [...] São nos cursos de graduação, na formação de novos professores e pesquisadores, que o pesquisador poderá fazer este intermédio [pesquisa e ensino] com seus futuros alunos.

Neste trabalho, tentamos apresentar a Teoria da Otimidade, em sua versão estocástica, como uma possibilidade de representação e compreensão do processamento gramatical fonológico na mente do aprendiz de inglês-LA. Trata-se de uma aproximação - necessá-

\footnotetext{
${ }^{27}$ Para uma revisão completa dos autores que consideram e desconsideram, em diferentes graus, $\mathrm{o}$
} acesso da GU na aquisição de LAs, ver Grédis (2016). 
ria, tal qual por nós concebida - da linguística formal à linguística aplicada ao ensino de LA, ofertando aos professores uma possibilidade de pensar a abstração teórica da linguística como um conhecimento diferencial e essencial para o aprimoramento de suas intervenções didáticas, no que concerne ao ensino de questões fonético-fonológicas. Além disso, a transferência de padrões da língua materna (português), muitas vezes concebida como negativa pelo professorado, é reinterpretada pelo modelo teórico que aqui utilizamos: não há "interferência” da língua materna na LA, há "interação" de restrições universais presentes em ambos os sistemas; produções “desviantes” da norma pré-estabelecida, tipicamente estigmatizadas em muitos ambientes de aprendizagem, são concebidas em uma perspectiva variacionista, que explica empírica e cientificamente os padrões produzidos. Assim, o conhecimento de gramática fonológica que aqui explicitamos não apenas associa teoria e prática, saber formal e saber aplicado, como também mune o professor de conhecimento teórico sobre sua área de atuação e o deixa alerta para uma perspectiva possível dos processos cognitivos que subjazem o processo de aquisição, aprendizagem e produção da fala na língua adicional alvo.

Por fim, conhecer a terminologia de uma área da ciência, ou dominar o uso de técnicas e procedimentos para a resolução de problemas - da forma como aqui exemplificamos através da representação do processo de aquisição da nasal velar pela TO Estocástica - ressalta a relevância fundamental do conhecimento teórico para melhor pensar em problemas práticos relativos ao ensino e à aprendizagem da fonologia de LA. A TO Estocástica, assim, traduz-se em uma (nem a melhor, nem a única) hipótese possível de compreensão do processo aquisicional. $\mathrm{O}$ conhecimento do professor em relação à teoria fonológica, qualquer que seja, é um posicionamento necessário para a fundamentação que embasa suas práticas didáticas, tornando suas atividades de ensino coerentes com seus princípios.

\section{Conclusão}

A forma com a qual apresentamos os conceitos de gramática aproximam-se da organização tripartite da linguística proposta por Campos (2007): a linguística é natural (mente/cérebro), é formal (lógica computacional) e também social (comunicação). À medida que a ciência desenvolve-se em meio a interfaces para expandir seu potencial explanatório, parece-nos adequado entender que a linguística formal é um conhecimento indispensável aos professores de línguas: "não é possível discutir ensino de língua de um jeito sério separado dessa formalização [fonologia, morfologia e sintaxe] a que nos referimos aqui” (SCHWINDT, 2014, p. 17). A TO Estocástica dispõe de uma proposta 
plausível para esse entendimento, mostrando-se um modelo teórico cujas bases epistemológicas são coerentes com a compreensão do processamento e da aprendizagem que o algoritmo expressa.

Considerar o ensino pelo viés internalista, como modelos derivados da hipótese da GU, pode auxiliar professores a pensar na aquisição mais seriamente, já que quanto mais informações tivermos a respeito dos princípios cognitivos que governam a aquisição, mais condições teremos de propor abordagens didáticas para maximizar a aprendizagem. Em relação ao acesso da GU na aquisição de outros sistemas, e da relevância da teoria fonológica para tal discernimento, Matzenauer e Azevedo (2016, p. 26) colocam que

$[\ldots]$ os fenômenos que se observam no uso da LE por aprendizes, desde o nível inicial ao avançado, são operações linguísticas da mesma natureza daquelas que podem integrar o uso do sistema por falantes nativos adultos ou por crianças em fase de aquisição da língua materna. As teorias fonológicas, portanto, dispõem de aparato para dar suporte às reflexões sobre o processo de aquisição de uma LE.

Para finalizar, retomamos a problematização feita em 1.3, declarando que:

mesmo que a aquisição decorra do desenvolvimento biológico do indivíduo, acreditamos que, dada a gama de usos/funções da língua como atividade social, o professor pode (e deve) exercer um papel de intervenção no processo de aquisição, favorecendo a aprendizagem;

a gramática fonológica é uma estrutura abstrata em desenvolvimento e o professor pode usufruir desse conhecimento teórico para explicitar aos aprendizes o seu funcionamento, fazendo comparações entre a língua materna e a língua adicional, propondo estratégias metacognitivas e contribuindo para o aperfeiçoamento gradual da fala dos aprendizes;

a gramática como entidade mental é o espaço onde as representações fonológicas estão. A forma com a qual o aprendiz paulatinamente organiza esse conhecimento, mediada pelo professor, habilita-o a intervir na estruturação da fonologia da LA e a fazer escolhas conscientemente adequadas com vistas aos seus objetivos discursivos. Afinal, a aquisição parece acontecer per se, mas a aprendizagem é dependente do sujeito que aprende e do professor-mediador que ensina.

Sabemos que a discussão não se encerra aqui. Quanto maior for o número de pesquisas a respeito da aquisição de LAs cujas gramáticas-base são o português brasileiro, 
mais hipóteses poderão ser construídas e testadas com vistas ao que a teoria fonológica vem oferecendo na linguística, tradicional e contemporaneamente.

\section{Referências}

ALVES, U. K. A explicitação dos aspectos fonético-fonológicos da L2: teoria e pesquisa em sala de aula. In: LAMPRETCH, R. et al. (Org). Consciência dos Sons da Língua: subsídios teóricos e práticos para alfabetizadores, fonoaudiólogos e professores de língua inglesa. Porto Alegre: EDIPUCRS, 2012a.

. Pesquisa em aquisição de L2 e ensino: um relacionamento possível (mas não necessariamente garantido). In: LEFFA, V. J.; ERNST, A. Linguagens. Metodologias de Ensino e Pesquisa. Pelotas: EDUCAT, 2012b.

. Aquisição Fonológica de L2: formalização de fenômenos variáveis na línguafonte, na língua-alvo e em seus sistemas intermediários. In: COLLISCHONN, G.; BISOL, L. Fonologia. Teorias e perspectivas. Porto Alegre: EDIPUCRS, 2013.

. Ensino de pronúncia na sala de aula de língua estrangeira: questões de discussão a partir de uma concepção de língua como sistema adaptativo e complexo. Versalete, v. 3, p. 392-413, 2015.

- Teoria da Otimidade Estocástica e Algoritmo de Aprendizagem Gradual: princípios de funcionamento e tutorial para simulação computacional. ReVEL, v. 15, p. 202-234, 2017.

; BAUER, D. A. O ensino comunicativo de pronúncia nas aulas de inglês (L2) para aprendizes brasileiros: análise de um livro didático. Linguagem \& Ensino (UCPel. Impresso), v. 14, p. 287-314, 2011.

; $\mathrm{O}$ ensino comunicativo de pronúncia na aula de inglês como LE: análise de livro didático. Artexto (FURG), v. 14, p. 9-19, 2013.

ALVES, F. C.; LUCENA, R. M. Aquisição da lateral silábica do inglês: uma análise via teoria da otimidade estocástica. Letrônica, Porto Alegre, v. 7, n. 2, p. 795-820, jul./dez., 2014.

AZEVEDO, R. Q. A epêntese no português brasileiro (L2), em segmentos plosivos em codas mediais, por falantes nativos do espanhol colombiano (L1): uma análise via Teoria da Otimidade Estocástica e Gramática Harmônica. 2011. 180 f. Dissertação (Mestrado em Linguística Aplicada) - Universidade Católica de Pelotas, Pelotas, 2011.

. AZEVEDO, R. Q. Formalização fonético-fonológica da interação de restrições na produção e percepção da epêntese no Português Brasileiro e no Português Europeu. Tese (Doutorado em Letras). Pelotas: Universidade Católica de Pelotas, 2016.

BISOL, L.; SCHIWNDT, L. C. (Orgs). Teoria da Otimidade: Fonologia. São Paulo: Pontes, 2010.

ULRICH, Camila Witt. Resenha de "Teoria da Otimidade: Fonologia”. ReVEL, vol. 15, n. 28,2017 
BOERSMA, P.; HAYES, B. Empirical Tests of the Gradual Learning Algorithm. 2001. Disponível em: http://www.linguistics.ucla.edu/people/hayes/GLA/gla.pdf. Acesso em: 23 outubro 2017.

; WEENINCK, D. Praat - Doing Phonetics by Computer. 2017. Disponível em: http://www.fon.hum.uva.nl/praat/download_win.html. Acesso em: 23 outubro 2017.

CAMPOS, J. Filosofia da Linguística, Filosofia da Ciência e Metateoria das Interfaces. 2007. Disponível em: http://www.jcamposc.com.br/textos_disciplinas/filosofia da_linguistica-filosofia_da_ciencia_e_metateoria_das_interfaces.pdf. Acesso em: 23 outubro 2017.

CERQUEIRA, F. O.; MARIANO, V. C. Algumas considerações sobre a evolução da linguagem: biolinguística e a noção de parâmetro. Inventário, no 19, Dez/2016, Salvador - Bahia.

CHOMSKY, N. Estruturas sintáticas. Tradução e comentários de Gabriel de Ávila Othero e Sérgio de Moura Menuzzi. Petrópolis: Vozes, 2015 [1957].

. Aspectos da Teoria da Sintaxe. Tradução de José Antonio Meirelles e Eduardo Paiva Raposo. Coimbra: Arménio Amado, 1975 [1965].

. A ciência da linguagem. Conversas com James McGilvray. Tradução de Gabriel de Ávila Othero, Luisandro Mendes Souza e Sérgio de Moura Menuzzi. São Paulo: Editora UNESP, 2014.

CRISTÓFARO-SILVA, T.; YEHIA, H. C. Desafios e perspectivas no ensino de fonética e fonologia. In: MARTINS, M. A. Gramática e Ensino. Natal: EDUFRN, 2013.

FRANÇA, A. I.; FERRARI, L.; MAIA, M. A Linguística no século XXI. Convergências e divergências no estudo da linguagem. São Paulo: Contexto, 2016.

FREITAS, M. A.; NEIVA, A. M. S. Estruturação silábica e processos fonológicos no inglês e no português: empréstimos e aquisição. Revista Virtual de Estudos da Linguagem - ReVEL. V. 4, n. 7, agosto de 2006.

GARCIA, G. D. Aquisição de acento primário em inglês por falantes de português: uma análise de derivações com sufixos não neutros via Algoritmo de Aprendizagem Gradual - GLA. 2012. 148 f. Dissertação (Mestrado em Letras) - Universidade Federal do Rio Grande do Sul, Porto Alegre, 2012.

GASPARETTO JR., A. Racionalismo. s/a. Disponível em: https://www.infoescola.com/ filosofia/racionalismo/. Acesso em: 23 outubro 2017.

GASS, S.; SELINKER, L. The role of the native language: an historical overview. In: . Second Language Acquisition. An introductory course. New York: Routledge, 2008.

GRÉDIS, R. A. A importância dos estudos sobre a Gramática Universal nas pesquisas em aquisição de segunda língua. Estudos linguísticos e literários, no 44, jul-dez/2016, Salvador: pp. 163-181. 
GREGG, K. R. Second language acquisition theory: the case for a generative perspective. In: GASS, S.; SCHACHTER, J. Linguistic Perspectives on Second Language Acquisition. New York: CUP, 1989.

GROLLA, E.; SILVA, M. C. F. Aquisição da linguagem. São Paulo: Contexto, 2014.

GUTIERRES, A. Variação na aquisição fonológica: análise da produção da nasal velar em inglês (L2). 2016. 206 f. Tese (Doutorado em Letras) - Universidade Federal do Rio Grande do Sul, Porto Alegre, 2016.

GUZZO, N.; GUTIERRES, A. A Produção Variável de Epêntese em Coda Final por Aprendizes de Inglês-L2. VII Senale. Pelotas: UcPel, 2013. Disponível em: http:// www. ucpel.tche.br/senale/cd_senale/2013/Textos/trabalhos/57.pdf. Acesso em: 23 outubro 2017.

HAHN, L. H. A Realização da Lateral /l/ no Inglês por Falantes do Português Brasileiro. 2010. 102 f. Dissertação (Mestrado em Letras) - Universidade Federal do Rio Grande do Sul, Porto Alegre, 2010.

HYMES, D. H. On communicative competence. In: PRIDE, J. B.; HOLMES, J. (Eds). Sociolinguistics. Selected Readings. Harmondsworth: Penguin, 1972.

HORA, D.; MATZENAUER, C. L. (Orgs). Fonologia, fonologias. Uma introdução. São Paulo: Contexto, 2017.

JENKINS, J. English pronunciation and second languague speaker identity. In: OMONIYI, T. WHITE, G. (Eds). The sociolinguistics of identity. New York: Continuum, 2006. p. 75-91.

KRASHEN, S. D. Principles and Practice in Second Language Acquisition. Pergamon Press, 2009 [1982].

KUPSKE, F. Second Language Pedagogy and Translation: The Role Of Learners' OwnLanguage and Explicit Instruction Revisited. Brazilian English Language Teaching Journal, v. 6, p. 51, 2015.

; ALVES, U. K. Orquestrando o caos: o ensino de pronúncia de Língua Estrangeira à luz do Paradigma da Complexidade. Fórum Linguístico (Online), 2017.

LEFFA, V. J.; IRALA, V. B. O ensino de outra(s) língua(s) na contemporaneidade: questões conceituais e metodológicas. In: - Uma espiadinha na sala de aula: ensinando línguas adicionais no Brasil. Pelotas: Educat, 2014.

MATZENAUER, C. L. Gramática(s) Fonológica(s) no processo de aquisição da linguagem: a construção do inventário segmental. Revista Prolíngua, n. 10, v. 1, jan/fev 2015.

; AZEVEDO, R. Q. Teoria Fonológica e Aquisição de Língua Estrangeira. In: ALVES, U. K. (Org.). Aquisição fonético-fonológica de língua estrangeira: investigações riograndenses e argentinas em discussão. São Paulo: Pontes, 2016. p. 25-48. 
MAURANEN, A. Conceptulising ELF. In: JENKINS, J.; BAKER, W.; DEWEY, M. The Routledge Handbook of English as a Lingua Franca. London: Routledge Handbooks in Applied Linguistics, 2018.

MOHANAN, T.; MOHANAN, K. P. Towards a Theory of Constraints in OT: Emergence of the not-so-unmarked in Malayalee English. Rutgers Optimality Archive - ROA \#601. 2003.

MOURA NEVES, M. H. A gramática. História, teoria e análise, ensino. São Paulo: Editora UNESP, 2002.

PRINCE, A.; SMOLENSKY, P. Optimality Theory: constraint interaction in generative grammar. In: McCARTHY, J. Optimality Theory in Phonology. Oxford: Blackwell Publishing, 2004 [1993].

SCHWINDT, L. C. (Org). Manual de Linguística. Fonologia, Morfologia e Sintaxe. Rio de Janeiro: Vozes, 2014.

SELINKER, L. On the notion of 'IL competence' in early SLA research: an aid to understading some baffling current issues. In: BROWN, G.; MALMKJAER, K.; WILLIAMS, J. (Eds.). Performance and competence in SLA. Cambridge: CUP, 1996. p. 92-113.

SWAN, M. Practical English Usage. New Edition. Oxford: OUP, 2003.

WHITE, L. The Responsibility of Grammatical Theory to Acquisitional Data. In: HORNSTEIN, N.; LIGHTFOOT, D. Explanation in Linguistics. The logical problem of language acquisition. Longman, 1981.

. On the Nature of Interlanguage Representation: Universal Grammar in the Second Language. In: DOUGHTY, C. J.; LONG, M. H. The Handbook of Second Language Acquisition. Blackwell, 2005.

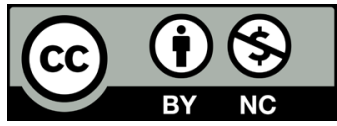

Data de submissão: $31 / 10 / 2017$

Data de aceite: $27 / 12 / 2017$ 